Check for updates

The BMJ

Cite this as: BMJ 2022;376:0480 http://dx.doi.org/10.1136/bmj.0480 Published: 24 February 2022

\title{
Covid-19: Severe infection in pregnancy significantly increases risks, study shows
}

Gareth lacobucci

Severe covid-19 infection in pregnant women significantly increases the risk of harmful outcomes for mothers and babies, a study has found. ${ }^{1}$

The study, led by researchers at Oxford Population Health, examined data from the UK Obstetric Surveillance System, ${ }^{2}$ which holds records for the 1.1 million women who gave birth in UK hospitals between 1 March 2020 and 31 October 2021.

Results, published in Acta Obstetricia et Gynecologica Scandinavica, show that in this period, 4436 pregnant women were admitted to hospital with confirmed covid-19 infection. Some $14 \%$ (616) had severe infection, $21 \%$ (917) had moderate infection, and 65\% (2903) had mild infection.

Marian Knight, Wellbeing of Women researcher and professor of maternal and child population health at the University of Oxford's National Perinatal Epidemiology Unit and lead author, said, "Most women give birth safely and have healthy babies, but we know that pregnant women are at greater risk of developing severe covid-19 infection, particularly in the third trimester. This can lead to tragic outcomes, including premature birth and stillbirth."

The study found that pregnant women with severe covid-19 infection were significantly more likely to have a preterm birth (<32 weeks' gestation adjusted odds ratio $10.75,95 \%$ confidence interval 7.78 to 14.85; <28 weeks aOR 12.35; $95 \%$ CI 6.34 to 24.05 ), to have a pre-labour caesarean birth (aOR 8.84, 95\% CI 6.61 to 11.83 ), to have a baby that was stillborn (aOR $2.51,95 \%$ CI 1.35 to 4.66), or to be admitted to a neonatal intensive care unit (aOR 11.61, 95\% CI 9.28 to 14.52$)$.

During this period, 22 women died, all with severe covid-19 infection during pregnancy, 59 babies were stillborn, and 10 infants died in the neonatal period.

Pregnant women at greater risk of severe covid-19 infection were more likely to be over 30 (aOR 1.48 $95 \% \mathrm{CI} 1.20$ to 1.83 ), be overweight or obese (aOR 1.73, 95\% CI 1.34 to 2.24 and aOR 2.52 95\% CI 1.97 to 3.23 , respectively), be of mixed ethnicity (aOR 1.93, 95\% CI 1.17 to 3.21, respectively), or have gestational diabetes (aOR 1.43, 61 95\% CI 1.09 to 1.87) compared with those with mild or moderate infection.

The data show that vaccination protects pregnant women from illness and the need for hospital admission, but the authors highlighted the latest vaccination figures showing that $73 \%$ of Asian women, $86 \%$ of black women, and $65 \%$ of white women were unvaccinated at the time of birth in October 2021.

The researchers also noted stark socioeconomic inequalities, with $82 \%$ of women from the most deprived areas of the country unvaccinated during birth, compared with $52 \%$ of women from the least deprived areas.

Knight added, "While vaccination rates are increasing, it is extremely concerning that pregnant women who are at most risk of severe infection are among the communities least likely to be vaccinated before giving birth. Local community engagement with vulnerable groups of women should be an urgent priority to tackle concerns and give reassurance about the vaccine."

The study was funded by the charity Wellbeing of Women and the National Institute for Health Research.

Vousden N, Ramakrishnan R, Bunch K, et al. Management and implications of severe covid-19 in pregnancy in the UK: data from the UK Obstetric Surveillance System national cohort. https://obgyn.onlinelibrary.wiley.com/journal/16000412

2 UK Obstetric Surveillance System. www.npeu.ox.ac.uk/ukoss.

This article is made freely available for personal use in accordance with BMJ's website terms and conditions for the duration of the covid-19 pandemic or until otherwise determined by BMJ. You may download and print the article for any lawful, non-commercial purpose (including text and data mining) provided that all copyright notices and trade marks are retained. 